\title{
A PERCEPÇÃO ESPACIAL A PARTIR DO ADVENTO DO TELEFOINE CELULAR: POSSÍVEIS IMPACTOS NA RELAÇÃO SUJEITO - LUGAR.
}

Lucas Fonseca de Macedo

lufsma@hotmail.com

Prof. Dr. Marcelo Faria

marcelo.faria65@gmail.com

\section{PALAVRAS CHAVE:}

Lugar; Percepção espacial, smartphones

\section{Introdução:}

Ao longo deste trabalho procuramos discutir a relação dos sujeitos com o lugar, o que implica investigarmos dois aspectos importantes dessa relação: a forma pela qual os indivíduos percebem o lugar e como essa percepção atua na orientação dos agenciamentos locais na produção espacial do lugar.

Estabelecemos como ponto de partida de nossa investigação - como um problema a ser investigado - a forma pela qual os indivíduos têm percebido o lugar a partir de sua existência mediada pelo uso intenso dos samartphones que, em nosso entender impacta de forma profunda e determinante a relação dos sujeitos com o lugar, gerando o que chamamos de experiência deslocalizada.

\section{Metodologia:}

Para o desenvolvimento das ideias desta pesquisa, realizou-se levantamento bibliográfico em materiais de referência acerca do conceito de lugar proposto por Doreen Massey (2005), experiência por Larrosa (2002) e a fenomenologia da percepção por Merleau-Ponty (1945), e desenvolvido na geografia pelo professor Ângelo Serpa (2019).

Havia inicialmente a intenção de elaborar uma série de atividades de Cartografia dos itinerários dos estudantes de graduação da UEFS para estabelecer relações entre o uso dos smartphones e a percepção espacial desses itinerários.

Com a pandemia não foi possível a realização dessas atividades. Sendo assim, optamos pelo desenvolvimento de uma discussão teórica sobre a percepção do lugar e os possíveis impactos gerados pelo uso intensivo dos smartphones, que altera as possibilidades de interação dos sujeitos com o contexto no qual estão situados e, por consequência no seu agenciamento como sujeito ativo na produção do lugar. 


\section{Discussão e resultados:}

Edward Relph resgata importância do conceito de lugar em meio ao processo de desidentificação dos indivíduos e grupos com o espaço de sua experiência. Doreen Massey (1994; 2005) compreende o lugar como um "lugar de encontro" de múltiplas trajetórias que compõem movimentos articulados em redes de relações e entendimentos sociais.

Se o lugar se define pela combinação de trajetórias, ele não é um produto, ou reflexo, de processos mais amplos de produção espacial, mas se produz no atrito entre trajetórias diversas que se realiza mediado, mas não reduzido, em materialidades objetivas, cuja percepção e significação são fundamentais para o agenciamento dos sujeitos na complexidade que é o lugar, e definem novas composições, arranjos e, claro, estratégias de apropriação e uso.

O lugar é importante na formação dos indivíduos e grupos. É através da experiência compartilhada no/do lugar que os sujeitos vão produzindo suas identificações, afiliações, crenças, comportamentos. Esse processo de subjetivação depende da qualidade da inserção dos indivíduos no espaço, das possibilidades de acesso às potencialidades materiais e imateriais de cada lugar. Esse acesso depende, por sua vez, da percepção dos elementos constitutivos do espaço, da existência compartilhada e da produção de significados que condicionam a compreensão, orientam agenciamentos e contribuem para a produção de um senso partilhado do espaço/lugar em toda sua complexidade e, claro, experienciado como instância política.

Essa indeterminação nos leva a advogar em favor da noção de experiência espacial dos indivíduos, ao invés de uma compreensão mais generalista e, por isso mesmo, abstrata, do lugar.

Para Larrosa, a experiência de ser-no-mundo não se constitui a partir de um conjunto de fatos que acontece diante dos indivíduos ou, dito de outra maneira, de uma vivência de acontecimentos que se sucedem em uma espacialidade (externa) qualquer, neutra. Para ele, o que caracteriza a experiência são os processos de significação e transformação que, nos indivíduos, acontecem, fruto dos atravessamentos que os acomete em sua relação intersubjetiva no mundo ou, sendo mais preciso, com a parcela do espaço no qual ele se encontra. Para ele, a experiência de ser-no-mundo não se constitui a partir de um conjunto de fatos que acontece diante dos indivíduos ou, mas o que caracteriza a experiência são os processos de significação e transformação que, nos indivíduos, acontecem, fruto dos atravessamentos que os acomete em sua relação intersubjetiva no mundo ou, sendo mais preciso, com a parcela do espaço no qual ele se encontra.

Se, em Relph, a tecnologia dificulta os processos de identificação e apropriação em função do rápido processo de destruição das paisagens gerado pelos avanços tecnológicos, para Massey, esse processo deverá ser investigado como a própria condição da experiência dos sujeitos que 
vivem mergulhados nessa complexidade. Massey (2005) nos alerta para o perigo de adotarmos uma concepção reducionista do lugar, desgarrada das experiências contemporâneas - objetiva e subjetiva - dos sujeitos que formulam o lugar como produto da globalização, a partir da submissão de todos os processos aos interesses do capital e dos grupos dominantes.

Sendo assim, pensar o lugar na contemporaneidade, implica reconhecer a presença dos smartphones e refletir em torno de seu impacto na constituição dos indivíduos, na forma como eles percebem e se relacionam com o lugar.

Neste contexto, a experiência espaço-temporal dos indivíduos e grupos adquire novos contornos que tem, como uma de suas características, mudanças na forma como atualmente experienciamos o "momento", plugados 24 horas por dia e sete dias por semana nas tecnologias comunicacionais, causando uma espécie de deslocalização dos indivíduos com seu entorno.

A experiência humana mediada pela tecnologia digital, marcada pela onipresença dos smartphones e pela circulação de informação em alta velocidade, nos faz pensar na dificuldade de se promover uma abertura para a experiência espacial do lugar, gerando o que chamaremos aqui de uma "vivência deslocalizada". Não se trata apenas de uma vivência deslocada para um outro lugar, mas no fechamento para a experiência situada dos indivíduos e grupos, operado pelo uso permanente do celular que permite o acesso parcial - e transferência do sujeito - a um local outro, minando a possibilidade de abertura e relação dos sujeitos com o acontecer situado

Consideramos ao final dessa investigação que a utilização intensiva dos smartphones pode corroborar como uma espécie de cisão nos sujeitos e na sua relação com o lugar, gerando nos indivíduos um "fechamento para" com o lugar, impactando por uma espécie de apartamento do corpo/mente na relação espacial imediata dos indivíduos e grupos, que contribui para o que estamos chamando de experiência deslocalizada, que desloca e (re)qualifica a experiência entre os sujeitos e lugar, provocando uma experiência pouco significativa dos sujeitos com o contexto imediato, cooperando - para o esvaziamento do sentido de lugar.

\section{REFERÊNCIAS:}

BONDIA, Jorge Larrossa; Notas sobre a experiência e o saber da experiência; Universidade de Barcelona, Espanha, 2002.

BUTTIMER, A. Apreendendo o dinamismo do mundo vivido. In: CHRISTOFOLETTI, Antônio (org). Perspectivas da Geografia. São Paulo: Difel, 1982.

HARVEY, David. A Condição Pós-moderna. Uma Pesquisa sobre as Origens da Mudança Cultural. Rio de Janeiro: Edições Loyola, 1996

MALPAS, Jeff - Place and Experience. New York. Cambridge University Press, 2007. 
MASSEY, Doreen - For Space. London: SAGE, 2005.

(org.) Human Geography Today. Ed Polity Press. Cambridge UK, 2007.

MERLEAU-PONTY, Maurice - Fenomenologia da Percepção. São Paulo. Ed WMF Martins Fontes, 2011.

Mc DOWELL A transformação da Geografia cultural. In: Gregory et al. Geografia Humana sociedade espaço e ciência social. São Paulo: Jorge Zahar Ed, 1996.

RELPH, Edward As bases fenomenológicas da Geografia. Geografia, Rio Claro, v.7, p. 1-26, 1979. Place and Placeness. London: Pion, 1976.

SANTOS, Milton. Por uma Geografia Nova. São Paulo: HUCITEC, 1978. (org.) Novos rumos da Geografia brasileira. São Paulo: HUCITEC, 1982. O espaço do cidadão. São Paulo: Nobel, 1987. Técnica-espaço-tempo: Globalização e meio técnico científico informacional. São Paulo: HUCITEC, 1994. A Natureza do Espaço técnica e tempo razão e emoção. São Paulo: HUCITEC, 1996.

SEVCENKO, Nicolau - A Virada para o Século XXI: no loop da montanha russa. São Paulo: Cia das Letras, 2005.

TUAN, Yi-Fu; Topoflia: um estudo da percepção. São Paulo: Difel, 1974.

TUAN, Yi-Fu. Espaço e lugar: A perspectiva da Experiência; Sâo Paulo: Difel, 1983

WASIAK, Jason. Ser-na-cidade: Uma aproximação fenomenológica da experiência tecnológica; Culture Unbound, 2009. 